\title{
Troponin I Levels and Postoperative Myocardial Infarction following Renal Transplantation
}

\author{
G.R. Shroff ${ }^{a}$ S.K. Akkina ${ }^{\text {c,d }}$ M.D. Miedema ${ }^{b}$ R. Madlon-Kay ${ }^{b}$ C.A. Herzog ${ }^{a}$ \\ B.L. Kasiske ${ }^{c}$ \\ ${ }^{\mathrm{a}}$ Division of Cardiology, Hennepin County Medical Center, and Divisions of ${ }^{\mathrm{b}}$ Cardiology and ${ }^{\mathrm{c}}$ Nephrology and \\ Hypertension, Department of Medicine, University of Minnesota, Minneapolis, Minn., and d Section of Nephrology, \\ Department of Medicine, University of Illinois at Chicago, Chicago, III., USA
}

\section{Key Words}

Troponin · Transplant • Myocardial infarction •

Postoperative

\begin{abstract}
Background: The relationship of routine postoperative troponin I (Tnl) monitoring in kidney transplant recipients and in-hospital myocardial infarction (MI) is not known. Methods: This observational study evaluated the prevalence of abnormal postoperative Tnl (Ortho Clinical Diagnostics assay) in 376 consecutive kidney or kidney/pancreas transplant recipients. In-hospital MI was adjudicated using the universal definition. Rates of death and coronary revascularizations at 1 year were studied. Logistic regression analysis was performed to identify independent predictors of abnormal Tnl. Results: Ninety-five (25\%) recipients had abnormal Tnl ( $>0.04 \mathrm{ng} / \mathrm{ml}$ ) following transplantation. Abnormal Tnl levels were more common in older (mean age: $52.2 \pm 13.4$ vs. 48.3 \pm 13.2 years, $p=0.01$ ), diabetic ( 57.9 vs. $45.6 \%, p=0.04$ ), and prior coronary artery disease (31.6 vs. $20.3 \%, p=0.02$ ) patients. In-hospital MI occurred in 6 patients (1.6\%). All subsequent in-hospital cardiovascular events occurred in the abnormal postoperative Tnl group; most in those with Tnl levels $>1 \mathrm{ng} / \mathrm{ml}$. Previous coronary artery disease was the only in-
\end{abstract}

\section{KARGER}

Fax +41613061234 E-Mail karger@karger.ch www.karger.com
(C) 2012 S. Karger AG, Basel

0250-8095/12/0352-0175\$38.00/0

Accessible online at:

www.karger.com/ajn dependent predictor of a postoperative $\mathrm{Tnl}$ level $>1 \mathrm{ng} / \mathrm{ml}$ in multivariate analysis (odds ratio 4.61, 95\% confidence interval 1.49-14.32). At 1 year there was no significant difference in death (3.2 vs. $1.8 \%, p=0.42)$ and borderline significant difference in coronary revascularization ( 5.3 vs. $1.4 \%, p=0.049$ ) in abnormal versus normal Tnl groups. Conclusions: In-hospital Ml was infrequent, but abnormal Tnl highly prevalent following renal transplantation. Normal Tnl levels following renal transplantation had a high negative predictive value in excluding patients likely to develop subsequent postoperative MI. The role of a higher Tnl cut-off for screening for postoperative $\mathrm{Ml}$ in high-risk subgroups deserves future prospective evaluation.

Copyright $\odot 2012$ S. Karger AG, Basel

\section{Introduction}

Cardiovascular (CV) disease accounts for $43 \%$ of all deaths in patients with end-stage renal disease [1]. In particular, the mortality rate of patients on maintenance dialysis following myocardial infarction (MI) is extremely high [2]. CV disease continues to remain the leading cause of mortality and morbidity following renal transplantation [3]. Renal transplant recipients have signifi-

Dr. Gautam R. Shroff

Cardiovascular Division, Hennepin County Medical Center

701 Park Avenue

Minneapolis, MN 55155 (USA)

Tel. +1 612873 2876, E-Mail shrof010@umn.edu 
cantly higher mortality rates compared to patients on dialysis in the first 3 months following transplantation; this risk is highest (about three-fold) in the first 2 weeks [4]. Perioperative MI following non-cardiac surgery is associated with an increased risk of in-hospital mortality, future cardiac death and recurrent MI [5]. Furthermore, $\mathrm{CV}$ complications following renal transplantation surgery are associated with long-term allograft dysfunction [6]. Since renal transplantation confers a significant survival advantage relative to patients on dialysis or waitlisted for transplantation in the long-term, early detection and appropriate management of early CV events is a clinical priority in renal transplant recipients.

It is well established that cardiac troponin levels are independent predictors of adverse long-term CV events and mortality in patients with chronic kidney disease and endstage renal disease [7, 8]. Apple et al. [9] showed in patients with end-stage renal disease that the adjusted relative risk of mortality associated with elevated troponin $\mathrm{T}(\mathrm{TnT})$ and troponin I (TnI) isoforms was 3.9 and 2.1, respectively. Connolly et al. [10] found that TnT levels are independently predictive of mortality in asymptomatic renal transplant recipients. Hickson et al. [11, 12] have demonstrated that TnT levels obtained in patients wait-listed for renal transplantation as well as obtained immediately pretransplantation are independently predictive of long-term survival. Additionally, Claes et al. [13] have shown that TnI levels obtained immediately pre-transplant are predictive of adverse $\mathrm{CV}$ events in the postoperative period.

However, pre-transplant troponins are rarely available to guide management in routine clinical practice. Moreover, the baseline prevalence of abnormal troponin levels in patients with renal failure is high, making it challenging to interpret elevated levels in the context of detecting early postoperative CV events $[7,14,15]$. In this observational study, we sought to investigate the prevalence of abnormal postoperative TnI levels in renal transplant recipients and their relation to subsequent postoperative $\mathrm{MI}$ and future $\mathrm{CV}$ events at 1 year.

\section{Methods}

The institutional review board at the University of Minnesota approved this study. All patients undergoing kidney and kidney/ pancreas transplantation at the University of Minnesota underwent routine measurement of TnI levels between November 1, 2005 and September 1, 2007 according to a surgical post-transplant management order set ( $3 \mathrm{TnI}$ level measurements $8 \mathrm{~h}$ apart after arriving from the operating room). A TnI level was considered abnormal if $\geq 0.04 \mathrm{ng} / \mathrm{ml}$ (Vitros ${ }^{\circledR}$, Ortho Clinical Diagnostics; re- ported imprecision $10 \% \mathrm{CV}$ at $0.04 \mathrm{ng} / \mathrm{ml}$ ). The first TnI level after arrival from the operating room and the highest among the three TnI values measured in the immediate postoperative period were recorded. The results of the post-transplant TnI levels were available in the routine care of the renal transplant recipients but clinical testing or management was not mandated by the order set. Postoperative transplant recipients were initially observed in the post-anesthesia care unit and then admitted to a telemetry floor for posttransplant management, with transfer to the intensive care unit reserved only for patients who demonstrated clinical instability.

We retrospectively studied the transplantation database to identify the incidence of in-hospital CV events (defined as death, MI, arrhythmia or heart failure). The diagnosis of in-hospital MI was retrospectively adjudicated by a single cardiologist (G.R.S.) based on the universal consensus criteria for MI defined by the combination of elevated TnI levels (above the $99 \%$ percentile and associated with rise and fall in TnI levels) plus any one of the following 3 criteria: symptoms of ischemia, changes on electrocardiogram of new ischemia/infarction, or imaging evidence of new ischemia/infarction [16]. In addition, the timing of the diagnosis of the in-hospital CV event was also recorded by retrospective chart review. Coronary revascularization procedures (percutaneous coronary intervention or coronary artery bypass graft surgery) were not recorded as in-hospital CV events due to the inability to determine if the revascularization was 'driven' by (i.e. if revascularization occurred as a result of) the abnormal postoperative $\mathrm{TnI}$ alone due to the retrospective nature of the study design. We evaluated the rates of death and coronary revascularization at 1 year following the transplantation procedure (including the immediate postoperative period).

$\chi^{2}$ analysis and Fisher's exact test were used to study the difference between categorical variables and the Student's t test was used for continuous variables. Logistic regression analysis of multiple clinical covariates was performed to identify independent predictors of abnormal TnI. These covariates included recipient age, gender, race, and cardiac risk factors including hypertension, diabetes, smoking and previous diagnosis of obstructive coronary artery disease or congestive heart failure. A forward selection process was used with a $\mathrm{p}<0.05$ entry criteria. Odds ratios (OR) and 95\% confidence intervals (CI) are presented for each significant measure. Due to low event rates, multivariate analysis for independent predictors of postoperative $\mathrm{CV}$ events was not feasible. All analyses were done using SAS 9.2 (Cary, N.C., USA).

\section{Results}

376 consecutive renal and renal/pancreas transplant recipients had postoperative TnI levels measured following transplantation in the study period. Ninety-five (25\%) recipients had at least one abnormal TnI value $(\geq 0.04 \mathrm{ng} /$ $\mathrm{ml})$ following transplantation; $37(9.8 \%)$ between $0.04-$ $0.10 \mathrm{ng} / \mathrm{ml}, 38(10.1 \%)$ between $0.11-0.99 \mathrm{ng} / \mathrm{ml}$, and 20 $(5.3 \%) \geq 1.0 \mathrm{ng} / \mathrm{ml}$. The baseline characteristics of the population studied are summarized in table 1. Compared to patients with normal post-transplant TnI levels, patients with abnormal TnI levels were older (mean age: 
Table 1. Baseline characteristics of the study population

\begin{tabular}{lcll}
\hline Clinical variables & $\begin{array}{c}\text { Abnormal } \\
\text { TnI }(\mathrm{n}=95) \\
(25.3 \%)\end{array}$ & $\begin{array}{l}\text { Normal } \\
\text { TnI }(\mathrm{n}=281)\end{array}$ & $\begin{array}{l}\mathrm{p} \\
\text { value }\end{array}$ \\
& $52.2 \pm 13.4$ & $48.3 \pm 13.2$ & 0.01 \\
\hline Mean age, years & $52(54.7)$ & $168(59.8)$ & 0.39 \\
Male sex & $40(42.1)$ & $118(42.0)$ & 0.98 \\
Deceased donor transplant & & & \\
Race & $84(88.4)$ & $238(84.7)$ & 0.37 \\
$\quad$ Caucasian & $4(4.2)$ & $16(5.7)$ & 0.58 \\
Black & $55(58.5)$ & $128(45.6)$ & 0.04 \\
Diabetes & $82(86.3)$ & $236(84.0)$ & 0.59 \\
Hypertension & & & \\
Previous cardiac history & $30(31.6)$ & $57(20.3)$ & 0.02 \\
CAD & $16(16.8)$ & $17(6.1)$ & 0.001 \\
CABG & $11(11.6)$ & $33(11.7)$ & 0.97 \\
PCI & $5(5.3)$ & $9(3.2)$ & 0.36 \\
CHF & $62(65.3)$ & $163(58.0)$ & 0.21 \\
Prior dialysis & $53(55.8)$ & $153(54.5)$ & 0.82 \\
$\quad$ Hemodialysis & $9(9.5)$ & $10(3.6)$ & 0.02 \\
$\quad$ Peritoneal dialysis & & & \\
Cause of ESRD & $69(51.6)$ & $113(40.2)$ & 0.05 \\
$\quad$ Diabetes & $10(6.3)$ & $19(6.8)$ & 0.88 \\
Hypertension & $29(10.3)$ & 0.95 \\
Polycystic renal disease & $10.5)$ & \\
\hline
\end{tabular}

Values denote numbers with percentages in parentheses, unless otherwise indicated. CAD = Coronary artery disease; $\mathrm{CABG}=$ coronary artery bypass grafting; $\mathrm{PCI}=$ percutaneous coronary intervention; $\mathrm{CHF}=$ congestive heart failure; ESRD = end-stage renal disease.

$52.2 \pm 13.4$ vs. $48.3 \pm 13.2$ years, $\mathrm{p}=0.01$ ), more likely to have diabetes ( 58.5 vs. $45.6 \%, \mathrm{p}=0.04)$ and a history of previous coronary artery disease (31.6 vs. $20.3 \%$, p = $0.02)$, especially coronary artery bypass graft surgery ( 16.8 vs. $6.1 \%, p=0.001$ ). Among patients with abnormal post-transplant TnI levels 78/95 patients (82\%) underwent preoperative $\mathrm{CV}$ risk testing (42 patients underwent preoperative stress testing and 47 patients underwent preoperative coronary angiography) whereas 17/95 (18\%) had no preoperative testing for $\mathrm{CV}$ risk stratification prior to renal transplantation.

Table 2 summarizes the cardiac events that occurred during the hospital stay and rates of coronary revascularization and death in a 12-month period following transplantation. Among patients with abnormal post-transplant TnI levels, 8 in-hospital cardiac events occurred; 6 MI, 1 cardiac arrest, and 1 heart failure. Notably, all inhospital CV events occurred in patients with abnormal routine postoperative $\mathrm{TnI}$ values, and most in-hospital cardiac events occurred in patients with a routine post-
Table 2. Cardiac events in the study population during the hospital stay and within 1 year after renal transplantation

\begin{tabular}{llll}
\hline Post-transplant events & $\begin{array}{l}\text { Abnormal } \\
\text { TnI (n=95) } \\
(25.3 \%)\end{array}$ & $\begin{array}{l}\text { Normal } \\
\text { TnI (n=281) } \\
(74.7 \%)\end{array}$ & $\begin{array}{l}\mathrm{p} \\
\text { value }\end{array}$ \\
& & & \\
\hline In-hospital cardiac events & $8(8.4)$ & 0 & $<0.001$ \\
$\quad$ MI & $6(6.3)$ & 0 & $<0.001$ \\
PCI & $3(3.2)$ & 0 & 0.02 \\
CABG & 0 & 0 & 1.0 \\
Death & 0 & 0 & 1.0 \\
Cardiac events in 1 year & & & \\
CABG & $2(2.1)$ & 0 & 0.06 \\
PCI & $4(4.2)$ & $4(1.4)$ & 0.12 \\
CABG or PCI & $5(5.3)^{*}$ & $4(1.4)$ & 0.05 \\
Death & $3(3.2)$ & $5(1.8)$ & 0.42 \\
\hline
\end{tabular}

Values are numbers with percentages in parentheses. $\mathrm{CABG}=$ Coronary artery bypass grafting; $\mathrm{PCI}=$ percutaneous coronary intervention. ${ }^{*}$ One patient had a PCI followed by CABG in a 6-month period in the same coronary distribution; counted as a single event for revascularization.

operative $\mathrm{TnI}$ value $>1 \mathrm{ng} / \mathrm{ml}$. 7/20 patients with routine postoperative $\mathrm{TnI}>1 \mathrm{ng} / \mathrm{ml}$ had an in-hospital cardiac event versus $1 / 75$ patients with $\mathrm{TnI}<1 \mathrm{ng} / \mathrm{ml}$ ( $\mathrm{p}<0.0001$ using $\chi^{2}$ analysis). When followed at 1 year, patients with abnormal TnI were more likely to undergo coronary revascularization (coronary artery bypass graft surgery or percutaneous coronary intervention) compared to patients with normal postoperative TnI values (5.3 vs. $1.4 \%$, $\mathrm{p}=0.049)$. However, mortality rates were not significantly different at 1 year ( 3.2 vs. $1.8 \%, \mathrm{p}=0.42)$.

Table 3 provides details of the in-hospital cardiac events occurring in patients following renal transplantation. Five patients were diagnosed to have non-ST elevation MI (NSTEMI) and 1 patient was diagnosed to have ST elevation MI (STEMI) during their hospital stay. Among these patients, 3 underwent emergent coronary revascularization during the hospital stay and 3 were medically managed. No in-hospital cardiac events occurred in patients with normal postoperative TnI levels. Most postoperative cardiac events occurred on postoperative days 0 or 1 . It was notable that the STEMI event occurred on postoperative day 4 . Although preoperative $\mathrm{TnI}$ levels were not available in this study, the first routine post-transplant TnI level was within normal limits for most patients who sustained a postoperative cardiac event, suggesting that these were not likely to be patients with chronically elevated TnI levels. Patients 1,2 and 3 described in table 3 needed to be transferred to the inten- 
Table 3. In-hospital cardiac events occurring in patients following renal transplantation

\begin{tabular}{|c|c|c|c|c|c|c|c|c|}
\hline $\begin{array}{l}\text { Patient } \\
\text { No. }\end{array}$ & $\begin{array}{l}\text { Age } \\
\text { years }\end{array}$ & Sex & $\mathrm{DM}$ & $\begin{array}{l}\text { First } \\
\text { study TnI }\end{array}$ & $\begin{array}{l}\text { Peak } \\
\text { study TnI }\end{array}$ & In-hospital cardiac event & $\begin{array}{l}\text { Timing } \\
\text { of event }\end{array}$ & Revascularization* \\
\hline 1 & 54 & M & yes & $<0.04$ & 10.8 & NSTEMI & POD 0 & PCI and CABG \\
\hline 2 & 58 & M & yes & 0.34 & 7.53 & Torsades de pointes/ventricular fibrillation (hyperkalemia) & POD 1 & None \\
\hline 3 & 36 & $\mathrm{~F}$ & yes & $<0.04$ & 4.75 & STEMI, cardiogenic shock, complete heart block & POD 4 & PCI \\
\hline 4 & 44 & M & yes & 0.07 & 4.57 & NSTEMI & POD 0 & None \\
\hline 5 & 70 & $\mathrm{M}$ & no & $<0.04$ & 4.3 & NSTEMI & POD 1 & PCI \\
\hline 6 & 58 & $\mathrm{M}$ & yes & $<0.04$ & 3.52 & NSTEMI and atrial fibrillation & POD 1 & None \\
\hline 7 & 71 & $\mathrm{M}$ & no & $<0.04$ & 1.13 & NSTEMI & POD 0 & CABG \\
\hline 8 & 57 & $\mathrm{M}$ & yes & $<0.04$ & 0.29 & Heart failure & POD 2 & None \\
\hline
\end{tabular}

$\mathrm{TnI}$ levels are presented in ng/ml. PCI = Percutaneous coronary intervention; DM = diabetes mellitus; POD = postoperative day.

* Revascularization rates at 12 months from index transplantation surgery.

Table 4. Clinical predictors of abnormal TnI using multivariate analysis (data presented as OR with 95\% CI)

\begin{tabular}{lll}
\hline & $\begin{array}{l}\text { TnI } \geq 0.04 \mathrm{ng} / \mathrm{ml} \\
(\mathrm{n}=95)\end{array}$ & $\begin{array}{l}\text { TnI }>1 \mathrm{ng} / \mathrm{ml} \\
(\mathrm{n}=20)\end{array}$ \\
\hline Age 40-60 years & $1.06(0.55-2.05)$ & $0.54(0.14-2.16)$ \\
Age $>60$ years & $1.66(0.78-3.55)$ & $0.85(0.19-3.84)$ \\
Male sex & $0.80(0.48-1.35)$ & $1.96(0.60-6.39)$ \\
Deceased donor & $0.85(0.51-1.43)$ & $0.80(0.29-2.23)$ \\
Black & $0.91(0.28-2.95)$ & $1.67(0.31-9.04)$ \\
Diabetes & $1.60(0.93-2.74)$ & $1.59(0.53-4.79)$ \\
Pre-CAD & $1.42(0.78-2.57)$ & $4.59(1.48-14.26)$ \\
Smoking & $0.91(0.55-1.50)$ & $0.76(0.28-2.08)$ \\
Hypertension & $0.98(0.48-2.01)$ & - \\
\hline
\end{tabular}

Pre-CAD = Prior diagnosis of coronary artery disease.

sive care unit from the post-transplant unit for clinical concerns (hypotension, arrhythmia, and shock, respectively).

Details of the multivariate analysis are presented in table 4. Pre-transplant diabetes was a predictor of postoperative $\mathrm{TnI} \geq 0.04 \mathrm{ng} / \mathrm{ml}$ (OR 1.68, 95\% CI 1.03-2.74) in univariate analysis but this relationship was not maintained after logistic regression analysis using multiple clinical correlates (OR 1.56, CI 0.92-2.67). Previous coronary artery disease was the only independent predictor of a postoperative $\mathrm{TnI}$ level $>1 \mathrm{ng} / \mathrm{ml}$ in univariate analysis (OR 5.46, 95\% CI 2.04-14.6) and in multivariate analysis (OR 4.61, 95\% CI 1.49-14.32). A cut-off value $>1 \mathrm{ng} / \mathrm{ml}$ for a routine post-transplant $\mathrm{TnI}$ had a diagnostic sensitivity of $88 \%$ and specificity of $96 \%$ for the detection of subsequent postoperative in-hospital cardiac events.

\section{Discussion}

This retrospective study examined the value of routine post-transplant TnI measurements in relation to postoperative MI and early cardiac events. Despite the high baseline prevalence $(25 \%)$ of abnormal post-transplant TnI levels, the incidence of perioperative MI was only 1.6\%. Notably, all in-hospital cardiac events occurred only in the abnormal post-transplant TnI group; and most cardiac events occurred in patients with a routine post-transplant $\mathrm{TnI}$ level $>1 \mathrm{ng} / \mathrm{ml}$. The occurrence of at least one abnormal postoperative TnI level immediately following renal transplantation was associated with increased rates of coronary revascularization but not mortality at 1 year.

Patients with renal failure have been shown to have a high baseline prevalence of abnormal TnI levels, albeit lower than the prevalence of abnormal TnT levels [11, 12, 15]. Claes et al. [13] obtained TnI levels in 331 kidney transplant recipients at the time of engraftment, and found that $11.5 \%$ patients had a TnI level $>0.07 \mu \mathrm{g} / \mathrm{l}$ (99th percentile). The difference in prevalence compared to our study likely reflects variations in the assay and the diagnostic cut-off value. The high baseline prevalence of abnormal TnI levels in renal transplant recipients can pose a management conundrum to the clinician attempting to balance the immediate postoperative risks and long-term risk of adverse CV outcomes portended by abnormal TnI levels. Elevated troponin values in patients with renal insufficiency have been shown to occur secondary to multiple clinical mechanisms other than ischemic heart disease, including left ventricular dilatation and systolic/ diastolic dysfunction [17]. Indeed, a majority of abnormal postoperative TnI levels in renal transplant recipients in 
our study were not associated with in-hospital MI. Additionally, abnormal postoperative TnI levels were predicted by demographics and clinical variables (age, coronary artery disease and diabetes). These clinical variables identify a population that needs to be targeted to prevent perioperative $\mathrm{CV}$ complications, irrespective of troponin levels [18].

Interestingly, in this study all patients with a cardiac event during their subsequent hospital stay had abnormal $\mathrm{TnI}$ in the immediate postoperative period. Thus, negative TnI immediately following renal transplantation had a high negative predictive value in excluding patients likely to develop in-hospital postoperative MI. Conversely, the $25 \%$ patients with an abnormal TnI level might deserve more focused clinical attention to identify those at risk of a future in-hospital cardiac event. In fact, patients with higher postoperative TnI levels $(>1 \mathrm{ng} / \mathrm{ml}$; $5.3 \%$ of the study population) were more likely to develop an in-hospital cardiac event. Use of a higher TnI threshold (e.g. $>1 \mathrm{ng} / \mathrm{ml}$ ), attention to a rise/fall in TnI levels and simultaneous electrocardiogram changes may help further refine a prospective screening strategy for early detection of postoperative cardiac events. The clinical and cost-effectiveness of such an approach should be comprehensively evaluated in a prospectively designed study.

TnI levels in this study also provide information pertaining to the timing of postoperative MI in renal transplant recipients. In most patients, the first postoperative TnI level was normal but 1 of the 3 postoperative study TnI levels was elevated (table 3). NSTEMI occurred in 5 patients and was diagnosed on postoperative day 0 or 1 . One patient sustained an STEMI that was detected on postoperative day 4; but notably this patient had a markedly abnormal routine postoperative TnI level prior to the diagnosis of the actual clinical event. This observation suggests the possibility of a ruptured plaque that occurred in the immediate postoperative period that later evolved into an ST segment elevation MI during the hospital stay. Postoperative MI most likely occurs either intraoperatively or immediately following surgery, corresponding to periods associated with significant hemodynamic stress in a pro-inflammatory milieu [5]. This period is associated with a confluence of factors contributing to a combination of increased coronary artery shear stress (precipitating plaque fissuring and thrombosis) and increased myocardial oxygen demand [5]. Routine post-transplant TnI elevation could signal more subtle myonecrosis caused by a ruptured or vulnerable plaque in the postoperative period that evolves later into a postoperative MI (as observed in patient No. 3 in our study).
The incidence of MI following renal transplantation in this study is identical to that reported by Humar et al. [19], who described a $6 \%$ risk of perioperative cardiac events including 1.6\% risk of MI among 2,694 renal transplants at the University of Minnesota over a span of 14 years. Claes et al. [13] reported a 3.3\% incidence of short-term cardiac events in a study of 331 renal transplant patients at the University Hospitals, Leuven. Coronary revascularization was incorporated in the primary endpoint in addition to death and MI in this study, explaining the higher incidence of cardiac events reported. Lentine et al. [20] evaluated 35,847 patients using the United States Renal Data System (USRDS) and determined that the incidence of postoperative MI (from administrative records) was $4.3 \%$. The lower incidence of MI in single-center studies compared to USRDS data likely reflects a combination of factors including patient selection, preoperative CV risk stratification, and possibly more aggressive medical management.

This study has limitations inherent to retrospective studies including selection and ascertainment bias. Because of the retrospective nature of the study it was not possible to determine precisely in what percentage of patients with cardiac events the routine TnI levels may have contributed to the diagnosis or altered the clinical course. It is possible that the routine postoperative TnI levels could have altered the clinician's approach and influenced patient management and outcomes in ways that cannot be detected by the retrospective study design. Similarly, it was not possible to accurately determine if patients had symptoms attributable to cardiac ischemia in the postoperative period. The absence of preoperative TnI levels is a limitation, but does reflect routine clinical practice wherein preoperative TnI levels are not usually available to the clinician. Moreover, the first postoperative TnI level was not elevated in most patients in this study, making it unlikely that these patients had significant baseline TnI elevation. The influence of preoperative cardiac risk stratification on postoperative cardiac events and $\mathrm{TnI}$ elevation is not known in this study. A randomized, controlled trial would be the best way of determining whether obtaining routine $\mathrm{TnI}$ levels after renal transplantation in the background of optimal medical therapy improves longterm outcomes. However, the results of the current retrospective study suggest that such a trial would need to be extremely large to achieve adequate statistical power because of the low incidence of postoperative cardiac events.

In conclusion, the low incidence of postoperative MI coupled with a high baseline prevalence of abnormal TnI levels in this population does not support a routine strategy of post-transplant TnI monitoring for the detection of 
early cardiac events in renal transplant recipients. This conclusion supports the recommendations of societal guidelines ('routine measurement of cardiac-specific troponin after non-cardiac surgery is more likely to identify patients without acute MI than with MI'), and justifies the applicability of these guideline recommendations to the renal transplant population [21]. However, the observation that every postoperative cardiac event was heralded by an abnormal TnI measurement in the immediate post-transplant period needs future prospective evaluation. The role of screening $\mathrm{TnI}$ in high-risk subgroups (e.g. those with coronary artery disease, or diabetics) and use of a higher cut-off TnI value (e.g. $>1 \mathrm{ng} / \mathrm{ml}$ ) for screening for postoperative MI deserves future prospective evaluation.

\section{Acknowledgment}

S.K. Akkina was supported by a research grant from the American Society of Transplantation and the National Institute of Diabetes and Digestive and Renal Diseases, Award Number K23DK084121.

\section{Disclosure Statement}

Dr. Herzog is a consultant for Abbott Laboratories. The other authors report no relevant disclosures/conflicts of interest.

The results presented in this paper have not been published previously in whole or part except in abstract format.

\section{References}

1 US Renal Data System. USRDS 2010 Annual Data Report: atlas of end-stage renal disease in the United States. Bethesda, Md.: National Institutes of Health, National Institute of Diabetes and Digestive and Kidney Diseases. 2010. http://www.usrds.org.

2 Herzog CA, Ma JZ, Collins AJ: Poor longterm survival after acute myocardial infarction among patients on long-term dialysis. $\mathrm{N}$ Engl J Med 1998;339:799-805.

- 3 Israni AK, Snyder JJ, Skeans MA, Peng Y, Maclean JR, Weinhandl ED, et al: Predicting coronary heart disease after kidney transplantation: patient outcomes in renal transplantation (PORT) study. Am J Transplant 2010;10:338-353.

4 Wolfe RA, Ashby VB, Milford EL, Ojo AO, Ettenger RE, Agodoa LY, et al: Comparison of mortality in all patients on dialysis, patients on dialysis awaiting transplantation, and recipients of a first cadaveric transplant. N Engl J Med 1999;341:1725-1730.

-5 Devereaux PJ, Goldman L, Cook DJ, Gilbert K, Leslie K, Guyatt GH: Perioperative cardiac events in patients undergoing noncardiac surgery: a review of the magnitude of the problem, the pathophysiology of the events and methods to estimate and communicate risk. CMAJ 2005;173:627-634.

-6 Ojo AO: Cardiovascular complications after renal transplantation and their prevention. Transplantation 2006;82:603-611.

-7 Abbas NA, John RI, Webb MC, Kempson ME, Potter AN, Price CP, et al: Cardiac troponins and renal function in nondialysis patients with chronic kidney disease. Clin Chem 2005;51:2059-2066.

-8 Sharma R, Gaze DC, Pellerin D, Mehta RL, Gregson H, Streather CP, et al: Ischemiamodified albumin predicts mortality in ESRD. Am J Kidney Dis 2006;47:493-502.
-9 Apple FS, Murakami MM, Pearce LA, Herzog CA: Predictive value of cardiac troponin $\mathrm{I}$ and $\mathrm{T}$ for subsequent death in end-stage renal disease. Circulation 2002;106:29412945.

10 Connolly GM, Cunningham R, McNamee PT, Young IS, Maxwell AP: Troponin T is an independent predictor of mortality in renal transplant recipients. Nephrol Dial Transplant 2008;23:1019-1025.

- 11 Hickson LJ, Cosio FG, El-Zoghby ZM, Gloor JM, Kremers WK, Stegall MD, et al: Survival of patients on the kidney transplant wait list: relationship to cardiac troponin T. Am J Transplant 2008;8:2352-2359.

12 Hickson LT, El-Zoghby ZM, Lorenz EC, Stegall MD, Jaffe AS, Cosio FG: Patient survival after kidney transplantation: relationship to pretransplant cardiac troponin T levels. Am J Transplant 2009;9:1354-1361.

13 Claes K, Bammens B, Evenepoel P, Kuypers D, Coosemans W, Darius T, et al: Troponin I is a predictor of acute cardiac events in the immediate postoperative renal transplant period. Transplantation 2010;89:341-346.

14 Sommerer C, Beimler J, Schwenger V, Heckele N, Katus HA, Giannitsis E, et al: Cardiac biomarkers and survival in haemodialysis patients. Eur J Clin Invest 2007:37:350-356.

$\longrightarrow 15$ Roberts MA, MacMillan N, Hare DL, Ratnaike S, Sikaris K, Fraenkel MB, et al: Cardiac troponin levels in asymptomatic patients on the renal transplant waiting list.

Nephrology (Carlton) 2006;11:471-476.
Alpert JS, Thygesen K, Jaffe A, White HD: The universal definition of myocardial infarction: a consensus document: ischaemic heart disease. Heart 2008;94:1335-1341.
17 Sharma R, Gaze DC, Pellerin D, Mehta RL, Gregson H, Streather CP, et al: Cardiac structural and functional abnormalities in end stage renal disease patients with elevated cardiac troponin T. Heart 2006;92:804-809.

18 Diamond GA, Kaul S: How would the Reverend Bayes interpret high-sensitivity troponin? Circulation 2010;121:1172-1175.

- 19 Humar A, Kerr SR, Ramcharan T, Gillingham KJ, Matas AJ: Peri-operative cardiac morbidity in kidney transplant recipients: incidence and risk factors. Clin Transplant 2001:15:154-158

20 Lentine KL, Brennan DC, Schnitzler MA: Incidence and predictors of myocardial infarction after kidney transplantation. J Am Soc Nephrol 2005; 16:496-506.

21 American College of Cardiology/American Heart Association Task Force on Practice Guidelines (Writing Committee to Revise the 2002 Guidelines on Perioperative Cardiovascular Evaluation for Noncardiac Surgery); American Society of Echocardiography; American Society of Nuclear Cardiology; Heart Rhythm Society; Society of Cardiovascular Anesthesiologists; Society for Cardiovascular Angiography and Interventions; Society for Vascular Medicine and Biology; Society for Vascular Surgery, Fleisher LA, Beckman JA, Brown KA, Calkins H, Chaikof E, Fleischmann KE, et al: ACC/ AHA 2007 guidelines on perioperative cardiovascular evaluation and care for noncardiac surgery: executive summary: a report of the American College of Cardiology/American Heart Association Task Force on Practice Guidelines (Writing Committee to Revise the 2002 Guidelines on Perioperative Cardiovascular Evaluation for Noncardiac Surgery). Anesth Analg 2008;106:685-712. 